\title{
Pearson and Responsibility: (Mis-)Understanding the Capabilities Approach
}

\begin{abstract}
Aboriginal Australian public intellectual Noel Pearson has gained prominence and influence for his brand of policy reform in Indigenous affairs by drawing upon the capabilities approach. This article challenges the coherence of Pearson's position, arguing that his unrelenting focus on personal responsibility leads him to conflate different elements within capabilities thinking. Pearson 1) mistakes social capabilities (to which people are entitled) for human potential to be unfolded and 2) casts and prescribes personal responsibility as a type of latent capability. The latter a) inverts the capabilities approach wherein phenomena such as personal responsibility arise as an effect of the realization of latent capabilities rather than serving as latent capabilities themselves and $b$ ) is at odds with the liberal basis of the capabilities approach that rejects imposing "good" ways of life on people. This is illustrated through reference to Pearson's advocacy of Direct Instruction teaching and engagement with the "real economy". The paper recognizes Pearson's contribution to the policy debate and that the problems he highlights are real, but argues that the remedial approaches adopted are problematic, including in terms of Pearson's stated stance against assimilationist policy agendas.
\end{abstract}

Keywords: Capabilities - Pearson - Aboriginality - Indigenous affairs - Liberalism

\section{Introduction}

In outlining his view of Aboriginal community regeneration, Noel Pearson has made repeated reference to the capabilities approach. ${ }^{1}$ Developed by the economist Amartya $\mathrm{Sen}^{2}$ and the political philosopher Martha Nussbaum, ${ }^{3}$ the approach seeks to establish the social conditions for humans to develop well-being. Among other purposes, the approach is a framework for analysing public policy and human development. The political programme is intended to create the conditions of political, social and economic "ableness" under which people can convert their natural but latent capabilities into valuable "functionings". ${ }^{4}$ Because of its association with political liberalism, the approach broadly rejects imposing "good" ways of life on people, preferring to promote the opportunity-aspect of freedom by which people seek to pursue well-being in accordance with their conceptions of the good.

Pearson has invested significant effort in numerous op-eds and papers attempting to distinguish his approach to Aboriginal regeneration. His main concern is to overcome the "poison" of welfare dependency, which he views as perhaps the most corrosive force in Aboriginal communities. ${ }^{5}$ In order to do this, he defends both

${ }^{1}$ Pearson's engagement with Sen's capabilities approach has been examined in A. Duhs and L. Davidoff, "Capabilities, rights and justice in the context of Australian Aboriginal welfare policy", Forum for Social Economics, vol. 39 (2010) and A. Duhs and L. Davidoff "Australian Aboriginal welfare policy: the perspectives of Milton Friedman, J. S. Mill and Amartya Sen", The International Journal of Interdisciplinary Social Sciences, vol. 3(10), 163-170.

${ }^{2}$ Amartya Sen, Commodities and Capabilities (New Delhi, 1987).

${ }^{3}$ M. C. Nussbaum, Creating Capabilities: The Human Development Approach (Cambridge, 2011).

${ }^{4}$ I. Robeyns, "The Capability Approach: A Theoretical Survey", Journal of Human Development, vol. 6 (2005), p. 95

${ }^{5}$ N. Pearson, "Passive Welfare and the Destruction of Indigenous Society in Australia", in Reforming the Welfare State, ed. P. Saunders (Melbourne, 2000), pp. 136-155; N. Pearson, Our Right to Take 
engagement in the "real" or market-driven economy 6 and the promotion of capabilities derived from a reading of Sen. ${ }^{7}$ To this end, he has endorsed, developed and introduced a Direct Instruction (DI) teaching programme. ${ }^{8}$ While Pearson has achieved substantial acclaim for his contribution to debates on Aboriginal affairs, there are serious problems in his adoption and deployment of capabilities and his desire to integrate DI teaching into that approach.

In this article, we work through these problems, beginning by clarifying the capabilities approach and explaining Pearson's conflation of elements within it. His emphasis on personal responsibility sees him invert the position of key elements functionings and capabilities - within the capabilities approach. This is clearest in his deployment of personal responsibility in the pursuit of well-being - a move which misrecognizes latent capabilities, justifies the imposition of personal responsibility via the "real economy", limits opportunity and risks treating people as means rather than ends. We argue that this miss-use of capabilities leads to the problematic (assimilationist) use of DI as an instrument of capabilities. Finally, we argue that there may be more effective means of dealing with irresponsibility, if indeed capabilities are Pearson's concern.

\section{Clarifying forms of capabilities}

The capabilities approach is often misunderstood. As Keith Dowding ${ }^{9}$ explains, capabilities exist in different forms. In the first case, capabilities proper are general categories of latent or undeveloped capabilities which exist naturally simply by virtue of our being born human. We then have abilities which are circumscribed by our individual, private capacities, such that, while we may have the ability to learn a language, we may not have the ability to learn all languages. In order to make use of our abilities, we need capabilities as ableness - Sen's social capabilities. These are the social resources we need in order to develop our complex latent capabilities into functionings. The key resources which underpin capabilities as ableness are associated with the sort of socio-political liberties in the Rawlsian tradition of political liberalism. Developing practical reason (a crucial latent capability) enables us to make choices arising from ableness in order to realize functionings. Functionings are our latent capabilities developed fully in accordance with a life that we find meaningful and valuable. In accordance with Aristotelian thinking, by developing functionings, we come to flourish. ${ }^{10}$ To this extent, there is a relationship between being and doing, such that as we develop our capabilities we become better at being human. ${ }^{11}$

Responsibility (Cairns, 2000); N. Pearson, "Radical Hope: Education and Equality in Australia", Quarterly Essay, vol. 35 (2009), pp. 8-11.

6 N. Pearson and L. Kostakidis-Lianos, Building Indigenous Capital: Removing Obstacles to Participation in the Real Economy (Cairns, 2004)

${ }^{7}$ N. Pearson,. The Cape York Agenda: Fundamental Transformation through Radical Reform (Cairns, 2005), accessed December 5, 2014, http://www.cyi.org.au/wpcontent/uploads/2011/08/Cape\%2520York\%2520Agenda\%2520final.pdf.

8 J. Walker, "Noel Pearson Teaching Model to Get \$22m", The Australian (July 1 2014), accessed December 5, 2014, http://www.theaustralian.com.au/national-affairs/indigenous/noel-pearson-teachingmodel-to-get-22m/story-fn9hm1pm-1226972990901.

9 K. Dowding, "Can Capabilities Reconcile Freedom and Equality?", The Journal of Political Philosophy, vol. 14 (2006), pp. 323-324.

${ }^{10}$ Aristotle, The Metaphysics (London, 2004), pp. 131; 256-257; M. C. Nussbaum, Women and Human Development: The Capabilities Approach, (Cambridge, 2001), pp. 43; 72; 78-79.

${ }^{11}$ I. Robeyns, "The Capability Approach in Practice", The Journal of Political Philosophy, vol. 14 (2006), p. 95. 
The relationship between latent capabilities and liberty as part of ableness is mediated by the important distinction between negative and positive liberty. ${ }^{12}$ In negative liberty, our liberty consists in our being free from obstacles to action. While most liberals associate negative liberty with the absence of political or physical constraints, there are those who include social, cultural and economic constraints. ${ }^{13} \mathrm{We}$ are free when we have choices to make, even if we do not benefit from those choices or make the choices at all. In positive liberty, freedom consists in our being able to achieve and exercise self-mastery by having the necessary functionings to make good decisions. Self-mastery depends neither directly on opportunity nor primarily on choice, though the likes of Mill ${ }^{14}$ would regard both as essential means of developing and exercising self-mastery. In negative liberty, a person in an Aboriginal community is free, for instance, insofar as they are there are no legal, social or economic obstacles to making choices in pursuit of a life they themselves value even if it is of little benefit to their well-being, whereas, in positive liberty, a person needs to be equipped with the psychological, social and economic abilities by which to exercise agency and pursue a life that is of direct benefit to their well-being.

The capabilities approach, with its concern for immanent potential and wellbeing, may appear to be concerned with positive liberty (Deneulin, ${ }^{15}$ among others, contends that it can be concerned with nothing else). However, it is actually most commonly articulated in terms of negative liberty insofar as it eschews inflicting or prescribing functioning by endorsing "political liberalism" in the Rawlsian tradition. Indeed, Sen ${ }^{16}$ holds that freedom consists of the "opportunity aspect" and "the extent to which people have the opportunity to achieve outcomes that they value and have reason to value", while Nussbaum does not wish to be "dictatorial about the good", instead "identifying certain capacities, liberties and opportunities that have value in any plan of life that citizens" pursue". ${ }^{17}$ The approach is, therefore, "a partial, not a comprehensive, conception of the good life", ${ }^{18}$ precluding the ability of states to promote particular capabilities. ${ }^{19}$ The overarching commitment is to the "principle of each person's capability, based on a principle of each person as an end", ${ }^{20}$ with respect for persons meaning that "Capability [as ableness], not functioning, [is] the appropriate political goal". ${ }^{21}$ The foundational commitment to capability means that it is inappropriate to prescribe or inflict functioning on people within the capabilities approach.

In order to provide social capabilities as ableness, the capabilities approach focuses, squarely, on the effect of resources on particular people, ${ }^{22}$ since "there is evidence that the conversion of goods to capabilities varies from person to person

\footnotetext{
${ }^{12}$ I. Berlin, Four Essays on Liberty (Oxford, 1969), pp. 118-179.

${ }_{13}$ A. Sen, Inequality Reexamined (Oxford, 1992); G. A. Cohen, Self-Ownership, Freedom and Equality (Cambridge, 1995); P. Van Parijs, Real Freedom for All (Oxford, 1995); J. Waldron, "Homelessness and the Issue of Freedom", in Liberal Rights: Collected Papers 1981-1991, ed. J. Waldron (Cambridge: 1993), pp. 309-338; P. Pettit, "Negative Liberty: Liberal and Republican", European Journal of Philosophy, vol. I (1993), pp. 15-38.

${ }^{14}$ J. S. Mill, On Liberty and Other Essays (Oxford, 1998).

15 S. Deneulin, "Perfectionism, Liberalism and Paternalism in Sen and Nussbaum's Capability Approach", Review of Political Economy, vol. 14, 4 (2002), pp. 497-518.

${ }^{16}$ A. Sen, Development as Freedom (Oxford, 1999), p. 291.

${ }_{17}$ Nussbaum, Women and Human Development, pp. 69; 148.

${ }^{18}$ Nussbaum, Women and Human Development, p. 74.

${ }^{19}$ Nussbaum, Women and Human Development, p. 69.

${ }^{20}$ Nussbaum, Women and Human Development, pp. 69; 5.

${ }^{21}$ Nussbaum, Women and Human Development, p. 87.

${ }^{22}$ Dowding, "Can Capabilities Reconcile Freedom and Equality?", pp. 324-325.
} 
substantially, and the equality of the former [resources] may still be far from the equality of the latter". ${ }^{23}$ This means concern for the particular external and internal influences on a person's ability to convert capabilities into functionings. ${ }^{24}$ The relevant factors, here, include health, lifespan, environment, labour arrangements, character traits and physical constitution. Those who suffer from certain disabilities or live in particularly remote areas require more resources to achieve functionings than others. ${ }^{25}$ Given the general relative deprivation and heterogeneity of Aboriginal peoples across Australia, it would seem imperative, then, that both additional resources and a diversity of approaches are required in order to enable functioning. In keeping with the concern for political liberalism and the importance of the material and personal contexts on which people ground their attempts to function, capabilities as ableness is designed to allow individuals and groups the resources and relationships to convert capabilities into functionings in ways that they themselves find meaningful. ${ }^{26}$

Central to the conversion of capabilities into functionings is practical reason, since this enables people to identify and interrogate goods in order best to pursue a flourishing life. ${ }^{27}$ For Sen, a flourishing life is seen to be grounded, not in "acting on someone else's behalf... in light of someone else's... goals" but, rather, in pursuing one's "own values and objectives". ${ }^{28}$ Although practical reason can only be developed socially, since it is a social skill derived from engagement with culturally constituted human beings, it cannot be prescribed or inflicted. People cannot develop practical reason under conditions of paternalism (though some, such as Claassen, ${ }^{29}$ argue that capabilities is dependent upon elements of paternalism) because they cannot exercise and explore choice. ${ }^{30}$ They are treated, in Kantian terms, as means rather than ends, permanently preventing their conversion of core capabilities into genuine functionings. One value of capabilities, then, is that the goal is to enable people to form and sustain meaningful (non-prescribed) relationships and to manage their own lives in accordance with their own commitments. This value is readily associated with the idea of personal choice.

Underpinning capabilities as a political approach is a commitment to legalpolitical equality, since this is a pre-requisite of the mutual and supportive relationships required to enable people to pursue particular ways of life that they have reason to value. ${ }^{31}$ Sen and Nussbaum follow Rawls in emphasising the priority of this form of equality in rights over material equality, favouring, in various different respects, a sufficientarianism in which there are thresholds above which material inequalities are permissible. ${ }^{32}$ However, as has been argued elsewhere, it is not at all clear that it is

${ }^{23}$ A. Sen, "Equality of What?", in Tanner Lectures on Human Values, ed. S. McMurran (Cambridge, 1980), p. 219.

${ }^{24}$ A. Sen, Rationality and Freedom (Cambridge, 2004), p. 486

${ }^{25}$ Sen, "Equality of What?", pp. 217-218.

${ }^{26}$ Robeyns, "The Capability Approach in Practice", pp. 357-358; Sen, "Equality of What?", p. 219; A. Sen, "The standard of living", in, The Standard of Living: The Tanner Lectures, ed. G. Hawthorn (Cambridge, 1987), pp. 36-37; Sen, Commodities and Capabilities, 30-31

${ }^{27}$ A. Sen, Commodities and Capabilities (Amsterdam, 1985), p. 10; Sen, Rationality and Freedom, 568570.

${ }^{28}$ Sen, Development as Freedom, pp. 18-19.

${ }^{29}$ R. Claassen, "Capability Paternalism", Economics and Philosophy, vol. 30 (2014), pp. 57-73.

${ }^{30}$ M. C. Nussbaum, "Women and Cultural Universals", in Pluralism: The Philosophy and Politics of Diversity, ed. M. Baghramian and A. Ingram (London, 2000), p. 219. See also Sen, Development as Freedom, p. 18.

${ }^{31}$ Nussbaum, Creating Capabilities, p. 41.

${ }^{32}$ M. C. Nussbaum, Frontiers of Justice: Disability, Nationality, Species Membership (Cambridge, 2006), p. 71. 
possible to circumscribe spheres of inequalities, meaning that material inequalities may impact upon the status of legal-political rights. ${ }^{33}$

While there are commitments to multiple realisability of immanent capabilities and the shaping of ableness in accordance with local political structures, Sen and Nussbaum are neither relativists nor particularly reticent in criticising cultural commitments which undermine the realisation of capabilities. ${ }^{34}$ Where traditions, such as slavery or gender oppression or female genital cutting prevent individuals from converting their capabilities into functionings, they believe that action is required to effect cultural change. ${ }^{35}$ As such, there are grounds for intervention where people's freedom as capabilities is contravened by others' behaviour. If, for example, Aboriginal Australian cultural commitments undermine the ability of people to convert their latent capabilities into functionings, then there is a prima facie reason to challenge or change those commitments in order that capabilities as ableness are upheld.

Accordingly, latent capabilities and capabilities as ableness are distinct but related. The latent form cannot be realized without the social form. While there is scope for diversity, not all cultural commitments are compatible with the political project and, thereby, helpful in assisting individuals in their personal projects of converting latent capabilities into functionings. Because they recognize the importance of relationships to functioning, Sen and Nussbaum need not be regarded as methodological individualists, but their concern for respect for persons means that they are ethical individualists, since all individuals matter equally. ${ }^{36}$ There is, then, promise for deploying capabilities in a context, such as Aboriginal Australian affairs, in which there is disadvantage, inequality and lack of opportunity.

\section{Responsibility}

Noel Pearson is widely recognized for mounting a powerful challenge to recent policy orthodoxy of Aboriginal affairs. The issues he highlights are real and require action, and the established means of dealing with those issues have been shown to be problematic. ${ }^{37}$ It is absolutely the case, for instance, that Aboriginal people suffer disproportionately from poverty and the lifestyle diseases which accompany it. ${ }^{38}$ Although sometimes exaggerated or distorted for political reasons, ${ }^{39}$ these are very serious problems and Pearson has done much to highlight the severity of the issues. ${ }^{40}$

${ }^{33}$ M. T. Johnson, Evaluating Culture (Basingstoke, 2013), p. 92; L. Wilde, "Marx, Morality and the Global Justice Debate", in The Legacy of Marxism, ed. M. T. Johnson (New York, 2012), pp. 117-133. ${ }^{34}$ See M. C. Nussbaum, "Non-relative Values: An Aristotelian Approach", in The Quality of Life, ed. M. C. Nussbaum and A. Sen (Oxford, 1993), pp. 242-269.

${ }^{35}$ Sen, Development as Freedom, p. 31; Nussbaum, "Women and Cultural Universals", p. 207

${ }^{36}$ Robeyns, "The Capability Approach: A Theoretical Survey".

${ }^{37}$ See D. Austin-Broos, "Quarantining Violence: How Anthropology Does It?", in Culture Crisis: Anthropology and Violence in Aboriginal Australia, edited by J. Altman and M. Hinkson, (Kensington, 2010) pp. 140-141; N. Pearson, "Nights when I dream of a better world: Moving from the centre-left to the radical centre of Australian politics", John Button Oration (2010), accessed December 5, 2014 , http://johnbuttonprize.org.au/about/news/post/noel-pearson-s-2010-john-button-oration-nights-when-idream-of-a-better-world-moving-from-the-centre-left-to-the-radical-centre-of-australian-politics.

${ }^{38}$ See N. Pearson, "Positive and Negative Welfare and Australias Indigenous Communities", Family Matters, vol. 54 (1999), pp. 30-35; Pearson, "Passive Welfare and the Destruction of Indigenous Society in Australia"; Pearson, Our Right to Take Responsibility.

${ }^{39}$ See K. McCallum and L. Waller, "Failed State of Health”, Arena, vol. 118 (2012), pp. 33-34

${ }^{40}$ See Aboriginal and Torres Strait Islander Social Justice Commissioner, 2008 Social Justice Report (Sydney, 2009); Austin-Broos, “Quarantining Violence: How Anthropology Does It?”, p. 139; Board of Inquiry into the Protection of Aboriginal Children from Sexual Abuse (BIPACSA). 2007. Little Children are Sacred. Northern Territory Government, p. 21; T. Rowse, "Re-Figuring 'Aboriginal Culture'”, in
Commented [MB1]: Self-indulgent self-citation? This doesn't your book is more on task - so you'd still get to cite it ()$^{-}$ (referencing would need adjusting)

Commented [MJ2R1]: Nah, I don't think so, to be honest. There is a distinctive claim made about circumscribing inequalities - that is is a distinctive claim made about circumscribing inequalities - the is source can be found. I'm not arsed about citing my book, but I do source can be found. I' $m$ not arsed about citing my book, but I do
think it necessary to reference that claim. If you can think of a better think it necessary to reference that claim. If you can think of a better
example of a response to Walzer, for example, we can use it, though. 
Moreover, his ${ }^{41}$ concern that assimilation has proven harmful, that there are traditional Aboriginal values through which to respond to current problems, ${ }^{42}$ and that alternative approaches should be adopted should provide grounds on which to advance new and divergent social goods. However, it is not clear that his diagnosis is complete, his prognosis most effective and his concern about assimilation followed through into an approach which avoids it.

His main thesis concerns three distinct, but related, conceptions of responsibility. ${ }^{43}$ As Emma Kowal ${ }^{44}$ succinctly notes, these are i) retrospective accounts, in which blame for historical, contemporary and future problems is apportioned, ii) prospective responsibility, which is almost synonymous with duty and the fulfilment of roles, and, iii), an ontological interrogation of responsibility as agency, insofar as Pearson seeks to establish the extent to which, in the context of structure, people are able to exercise responsibility. Hence his refrain of "personal responsibility".

According to Pearson, ${ }^{45}$ retrospective responsibility for Aboriginal disadvantage lies, not primarily with the massacres, expropriations and oppressions of early to fairly recent colonialism, but the related introductions of grog and wellintentioned, but passive, welfarism. ${ }^{46}$ Prior to colonialism, he argues that Aboriginal people were forced to take prospective responsibility for themselves since living in environmental conditions which necessitated individuals working actively to sustain themselves through extended kin networks meant that there was nobody else to blame. By virtue of this harsh reality, people developed the capacity to exercise responsibility. That is to say, they were agents. In this respect, robust demand sharing ${ }^{47}$ obligations to kin did not result in passivity among community members, since individuals did not have limitless wealth or resources by which to support feckless relatives. In Pearson's eyes, Aboriginal society was one which traditionally emphasized personal responsibility. ${ }^{48}$

Today, however, the government has accepted, in Pearson's eyes, retrospective responsibility for the condition of Aboriginal people by virtue of its recognition of the

Culture Crisis: Anthropology and Violence in Aboriginal Australia, ed. J. Altman and M. Hinkson (Kensington 2010), p. 155.

${ }^{41}$ Pearson, "Radical Hope: Education and Equality in Australia"; N. Pearson, "A Rightful Place: Race, Recognition and a More Complete Commonwealth", Quarterly Essay, vol. 55 (2014), pp. 1-72.

${ }^{42}$ See E. Watt, "The implementation of the capabilities approach in Cape York: Can paternalism be a pre-condition for participation?", Development Bulletin, vol. 75 (2013), p. 39.

${ }^{43}$ See N. Pearson, New Approaches to Indigenous Policy: The Role of Rights and Responsibilities (Cairns, 2006).

${ }^{44}$ E. Kowal, "Responsibility, Noel Pearson and Indigenous Affairs in Australia", in Responsibility, ed. G. Hage and R. Eckersley (Melbourne, 2012), pp. 43-56.

${ }^{45}$ In particular, Pearson, Our Right to Take Responsibility; N. Pearson, "An abyss beyond the bottle", The Australian (14 July 2007)__, accessed December 5, 2014 , http://www.theaustralian.com.au/opinion/columnists/an-abyss-beyond-the-bottle/story-e6frg7861111113953532

${ }^{46}$ J. Altman, "Noel Pearson's policies embraced by white Australia, but how effective are they?", The Conversation, (August 9 2011), accessed December 5, 2014, http://theconversation.com/noel-pearsonspolicies-embraced-by-white-australia-but-how-effective-are-they-2226; Watt, "The implementation of the capabilities approach in Cape York: Can paternalism be a pre-condition for participation?”, p. 39

${ }^{47}$ See N. Pearson, "Shared Descent into the Maelstrom of Addiction", The Australian (October 132012 ) accessed December 5, 2014, http://cyi.org.au/wp-content/uploads/2012/11/Shared-Decent-into-themaelstrom-of-addiction_13-Oct-2012-Noel-Pearson.pdf; N. Peterson, "Demand Sharing: Reciprocity and the Pressure for Generosity among Foragers", American Anthropologist, vol. 95 (1993), pp. 860874.

${ }^{48}$ See Watt, "The implementation of the capabilities approach in Cape York: Can paternalism be a precondition for participation?". 
harms of colonialism. While it would not be possible to avoid such retrospective responsibility, the state has compounded that retrospective responsibility by failing to appreciate the true source of contemporary harms, continuing to exercise prospective responsibility by perpetuating harms associated with passive welfarism. The welfare system, Pearson argues, has excluded Aboriginal people from the "real economy" and interacted with historical Aboriginal cultural commitments to demand sharing to reinforce the passivity of welfare dependency, creating a situation in which those who do seek to get ahead through education, enterprise and labour are dragged down by their peers who leech their resources and condemn them for "selling out". 49 This creates a disincentive for taking prospective responsibility for one's future and that of one's community, ${ }^{50}$ as success means being beholden to kin who resent success while simultaneously being dependent upon it. This means that people are prevented or dissuaded from actively developing responsibility as agency. This problem, in Pearson's eyes, is worsened further by an apparent propensity among Aboriginal people towards addictive behaviour, particularly with regard to alcohol ${ }^{51} \mathrm{He}$ adds, with regard to demand sharing, that

when you add addiction to foreign substances and habits to this culture, things that are admirable and beautiful become deformed and destructive. Demand sharing and alcohol just don't mix. Alcohol (and other addictive substances and processes such as gambling) cannot be managed when people are subject to such intense obligations to share as Aboriginal people are with their relatives and countrymen. The problem is most pronounced in discrete communities, where you have all of your relatives and countrymen around you. ${ }^{52}$

Not only were Aboriginal people unprepared for grog, once it did arrive, welfare dependency amplified its consequences, leaving no reason or duty for people to stay sober, but leaving kin demand sharing obligations in place to support irresponsible drinkers as they destroyed themselves and their families. ${ }^{53}$ As such, historically beneficial Aboriginal cultural commitments are, today, transformed into deleterious path dependencies. The destructive behaviour enabled by these path dependencies inflicts capability failure on both the irresponsible individuals themselves and the people who have to support them.

Pearson's response to this is to emphasize the retrospective responsibility of welfarism in order to try to requisition prospective responsibility for Aboriginal people and create incentives for exercising responsibility as agency. For this, he turns first to

\footnotetext{
${ }^{49}$ See Pearson,- The Cape York Agenda: Fundamental Transformation through Radical Reform; N. Pearson, "Choice is not enough", The Australian, (28 April 2007), accessed December 5, 2014, http://www.theaustralian.com.au/opinion/noel-pearson-choice-is-not-enough/story-e6frg6zo1111113425904?nk=d74f947c42ed2714bb7343062e0ee685; Pearson, "Radical Hope: Education and Equality in Australia”, pp. 8-11; also, in parts, M. Langton, “A New Deal? Indigenous Development and the Politics of Recovery", Dr Charles Perkins AO Memorial Oration (University of Syndey Sydney, October 4 2002).

${ }^{50}$ See Pearson, “A Rightful Place: Race, Recognition and a More Complete Commonwealth”, pp. 45; 49.

${ }^{51}$ N. Pearson, "White Guilt, Victimhood and the Quest for a Radical Centre", Griffith REVIEW, vol. 16 (2007), accessed December 5, 2014, http://griffithreview.com/edition-16-unintendedconsequences/white-guilt-victimhood-and-the-quest-for-a-radical-centre/all-pages; Pearson, "Choice is not enough".

52 Pearson, "Shared Descent into the Maelstrom of Addiction".

${ }^{53}$ Pearson, "Radical Hope: Education and Equality in Australia", pp. 19-25.
} 
self-interest, arguing that, if people are to regain control over their lives, they must do so individually:

There was no mass elevator for entire communities or groups to ascend all at once. There are just the stairs, and no man is exempted from the need to climb in the same manner as one of Clarence's murderers in Richard the Third answered the means by which he had come hither: "on my legs". Individuals climb with their own legs on behalf of themselves and their families, in pursuit of their own interests.... the most powerful engine at the centre of development is the self interest of individuals seeking a better life for themselves. ${ }^{54}$

This explains his ${ }^{55}$ claim that "Indigenous Australians now want our equal liberty. We want the freedom to take responsibility" for choices.

Next, Pearson enlists Sen's capabilities approach. In his "Choice is not enough" op-ed for The Australian, he ${ }^{56}$ argues that "without capabilities, choice can be a hollow conceit". If Pearson means that, without adequate resources and the application of practical reason by which to make use of opportunities apparent in modern Australian society, then choice is hollow, then he has a point with which most capability theorists would surely agree. However, conceptual clarity with regard to his use of capabilities is missing.

\section{Conflating forms of capabilities}

Pearson's response to the issue of choice is two-fold and, in the terms of the capabilities approach, problematic. In the first case, Pearson argues that economic development is needed in order to create "capabilities" of income and employment, health and environment, education and community and citizenship. ${ }^{57}$ But this is to misunderstand simple ableness (the resources necessary for converting latent capabilities into functionings) as either latent capabilities or functionings themselves. Sen clearly refers, in this context, to health, education and the like as social capabilities to which people are entitled rather than human potential to be unfolded. Pearson's re-casting of capabilities language neglects the requirement to develop the latent capability of practical reason in a social context of ableness in order to realize functionings. Where Sen and Nussbaum are concerned to facilitate the flourishing of capabilities through ableness, Pearson advocates a program (via the "real" economy) to prescribe and inflict functionings, thereby treating people as means, rather than ends, thus defeating the Kantian ethical commitment which underpins the capabilities approach.

Furthermore, the sort of economic development that Pearson favours often appears to converge closely with neoliberal economic models, promoting as he does the creation of capital through the exploitation of natural and social resources for personal profit under conditions of the free market. ${ }^{58}$ As others have argued, ${ }^{59}$ the

\footnotetext{
${ }^{54}$ Pearson, "Nights when I dream of a better world: Moving from the centre-left to the radical centre of Australian politics".

${ }^{55}$ Pearson, “A Rightful Place: Race, Recognition and a More Complete Commonwealth”, p. 44.

${ }^{56}$ Pearson, "An abyss beyond the bottle".

${ }^{57}$ See Pearson, The Cape York Agenda.

${ }^{58}$ R. Connell, "Understanding Neoliberalism", in Neoliberalism and Everyday Life ed. S. Braedley and M. Luxton (Montreal, Quebec, 2010) pp. 34-35.

${ }^{59}$ H. Dean, "Critiquing capabilities: the distractions of a beguiling concept", Critical Social Policy, vol. 29, 2 (2009), pp. 261-273; T. Piketty, Capital in the 21 ${ }^{\text {st }}$ Century (Cambridge, 2014); G. Standing, Precariat: The New Dangerous Class (London, 2011); Wilde, "Marx, Morality and the Global Justice
} 
benefits of this sort of development are seldom distributed effectively to the sort of people Pearson cites as beneficiaries. Indeed, this base form of development contradicts Sen's concerns regarding the provision of welfare services as an integral means of upholding freedom and promoting growth. ${ }^{60}$ More generally, there are serious concerns about the viability of the "real economy" in the areas most in need of action on account of their being remote and environmentally uneven. ${ }^{61}$ Questions of production and distribution aside, for wealth to be more than a mere resource, it needs to be associated with a range of appropriate, supportive relationships. It is not clear that the sort of arrangements Pearson promotes achieve this. Competition, for example, may produce greater efficiency, but it also raises serious questions about those excluded from the "real economy" on grounds of efficiency, particularly with regard to the possibility that their sense of alienation may be compounded by the notion that they are of little value beyond their labour.

In the second case, through his focus on personal responsibility, Pearson mistakenly presents functionings as capabilities and suggests, counter to the capabilities approach, that these be prescribed - in effect inflicted on people. He returns, time and again, to the notion of personal responsibility. He states that his formula for capabilities is "Personal Responsibility + Opportunity = Capabilities", arguing that one "can well have many opportunities in the welfare state, but if someone does not take personal responsibility, then no capabilities will be developed". ${ }^{2}$ However, returning to the clarification offered by Dowding, we see that Pearson turns the capabilities approach on its head. In the capabilities approach, latent capabilities (which exist naturally simply by virtue of our being born human), with the affordance of opportunities (political, social and economic conditions), develop into functionings and human flourishing. Personal responsibility may arise as an effect of this pathway as a functioning or a byproduct of the application of practical reason, but it cannot be an "input" in a capabilities equation - it is not a latent capability. As a result, the outcome in Pearson's equation (capabilities) is cast as an end whereas the entirety of the capabilities approach actually rests of the premise that capabilities in both latent and ableness forms are means to human functioning and flourishing. Pearson's rendering inverts the capabilities approach because personal responsibility (an effect of the flourishing of latent capabilities), is shoe-horned into serving as a means of achieving things that already have to have been achieved in order for personal responsibility itself to existto arise.

If we are to understand the potential deployment of the capabilities approach in the policy context of Aboriginal affairs while taking seriously the issue of irresponsibility that Pearson highlights, we have to rejig the equation and reconsider the notion of personal responsibility. The appropriate equation should be: Latent capabilities + ableness (opportunity) $=$ functionings. The functionings of relevance here are those conducive to responsible behaviour. Pearson is surely right to think that responsibility is conducive to personal and collective well-being, but, philosophically, it is not a latent capability socially realized. Personal responsibility would seem, in any scheme, to be the fulfilment of roles or duties, in this case specifically with regard to pursuing productive ends and not burdening kin with destructive behaviour. The central

Debate"; R. Wilkinson and K. Pickett, The Spirit Level: Why Equality Is Better for Everyone (London, 2010), ete.

${ }^{60}$ Sen, Development as Freedom, p. 15.

${ }^{6}$ See J. Altman, "Alleviating poverty in remote Indigenous Australia: The role of the hybrid economy", Development Bulletin, vol. 72 (2007), pp. 47-51.

${ }^{62}$ Pearson, "Nights when I dream of a better world: Moving from the centre-left to the radical centre of Australian politics". 
latent capability behind the fulfilment of roles or duties is, of course, practical reason. Without practical reason, responsibility in this institutional form is either impossible, since the bases of its performance are unintelligible to the actor, or meaningless, since it is the mere repetition of action, as Mill would put it. Accordingly, if we are to make sense of Pearson's scheme, his equation should be: Latent capability of practical reason + ableness (means of converting that capability into a particular functioning in a particular context/role) $=$ functioning of practical reason as the basis for responsible fulfilment of roles or duties. As such, practical reason returns as the central capability to be advanced. However, Pearson's concern for personal responsibility, and his attempt to force the issue by prescribing it as a type of latent capability, means that he advocates policies which may undermine the very capability that is necessary in order to make his approach meaningful.

\section{Diminishing choice to increase personal responsibility}

Practical reason enables us to see that addictive behaviour is destructive, not only to us as individuals, but also to those we care about most. By developing practical reason as our ableness expands socially, we diminish those ills and advance collective well-being. In order to do this, we need to practice choice in order to achieve substantive functioning. Rather than viewing alcohol and other vice as choices to be addressed through the development of practical reason, however, Pearson seems to suggest that we are better served by reducing or eliminating choice. He argues that living according to certain traditional commitments while claiming welfare ${ }^{63}$ is choice rather than necessity, "choice without consequence", and "choice without responsibility". ${ }^{64}$ Men, in particular, have made the choice to be unproductive or self-destructive, ${ }^{65}$ often slipping "into aimlessness". ${ }^{66}$ Moreover, he claims that "indigenous and other disadvantaged Australians allow broad pathways for their young in their developing years, ending up with narrow choices upon adulthood"67 as the consequences of bad choices curtail choices later in life.

A recurrent theme in Pearson's response to this is to endorse forms of paternalism which cut the number of choices people face and, by promoting the remaining "good choices", inculcate a spirit of responsibility towards the pursuit of those choices. ${ }^{68}$ In effect, it often seems that Pearson ${ }^{69}$ believes that Aboriginal people need fewer choices, rather than better choice making abilities (informed by practical reason, for instance). This is demonstrated in part by his qualified support ${ }^{70}$ for the Northern Territory Emergency Response (NTER) or "-Intervention" (NTER) of 2007, which introduced controls on alcohol and pornography and quarantines on welfare payments in certain communities, his development of a system of conditional welfare

${ }^{63}$ N. Pearson, Up from the Mission: Selected Writings (Collingwood, 2009), p. 329.

${ }^{64}$ Pearson, "A Rightful Place: Race, Recognition and a More Complete Commonwealth", p. 49.

${ }^{65}$ N. Pearson, "White Guilt, Victimhood and the Quest for a Radical Centre", Griffith REVIEW, vol. 16 (2007), accessed December 5, 2014, http://griffithreview.com/edition-16-unintendedconsequences/white-guilt-victimhood-and-the-quest-for-a-radical-centre/all-pages.

${ }^{66}$ R. Broome, Aboriginal Australians: Black Responses to White Dominance 1788: 1994 (St Leonards, NSW, 2002), p. 151; see also Watt, "The implementation of the capabilities approach in Cape York: Can paternalism be a pre-condition for participation?", p. 39

${ }^{67}$ Pearson, "White Guilt, Victimhood and the Quest for a Radical Centre".

${ }^{68}$ Watt, "The implementation of the capabilities approach in Cape York: Can paternalism be a precondition for participation?", p. 40.

${ }^{69}$ Pearson, "Choice is not enough".

70 See Australian Broadcasting Corporation, "Noel Pearson discusses the issues faced by Indigenous communities", Lateline (June 26 2007), accessed December 5, 2014, http://www.abc.net.au/lateline/content/2007/s1962844.htm. 
payments in Cape York communities through the Cape York Welfare Reform Trial $(\mathrm{CYWRT})^{71}$ and his more recent development of Direct Instruction Teaching. ${ }^{72}$

While the constraints on choice introduced by the NTER are explicit, the intentions and effects of DI seem similarly constrictive. The approach is presented in the following form by its founder, Zig Engelmann:

Direct Instruction is basically a simple way of teaching things so that a couple of things happen: one - e everything you introduce will be consistent with only one interpretation - there will be no confusion. And then the second thing is, we want to try to sequence it out so that it is doled out only one new thing at a time.... If it's easy, it's because you've simplified the hard.... The idea is to teach all the kids as quickly as possible. That you're able to accelerate learning because you're not going to reach tough spots... To provide kids with an education that would permit them to make the maximum number of choices about their future. You're going to teach all those kids and you're going to teach them all the things they need to know. ${ }^{73}$

The programme appears to tie in with Sen's approach insofar as it aims to develop to an above subsistence level of decision making capabilities and educate those from the most disadvantaged backgrounds. ${ }^{74}$

There is evidence that DI is effective in developing basic reading skills among disadvantaged children, enabling them to dismiss "irrelevant" or confusing information in order to focus on things which are identified by the programme as important. ${ }^{75}$ However, the notion that DI, with its scripted, inflexible lessons taught by teachers who are afforded power as the source of all knowledge in the pedagogical relationship, serves to enable children meaningfully to make choices is problematic. As Luke ${ }^{76}$ reports, there is concern that "asymmetrical relationships of power and knowledge in the DI model... subordinates and mis-recognizes student and community background knowledge, cultural experiences and prior knowledge schemata". There is evidence to suggest that the homogenising approach of DI fails to engender in children the exploratory and independent thinking behind-necessary for practical reason. ${ }^{77}$ While

\footnotetext{
${ }^{71}$ Cape York Aboriginal Australian Academy, “About us", Cape York Aboriginal Australian Academy (2014), accessed December 5, 2014, http://cyaaa.eq.edu.au/about-us/index.html; Altman, "Noel Pearson's policies embraced by white Australia, but how effective are they?"; J. Falzon and S. Cowling, "Tackling poverty: Time for fresh thinking and a look at the evidence", Online Opinion, (20 October 2010), accessed December 5, 2014, http://www.onlineopinion.com.au/view.asp?article=11121\&page=0

${ }^{72}$ See Pearson, “A Rightful Place: Race, Recognition and a More Complete Commonwealth"; Cape York Aboriginal Australian Academy, "About us".

${ }^{73}$ Direct Instruction Teaching, "Zig Engelmann Discusses Direct Instruction”, YouTube (2013), accessed December 5, 2014, https://www.youtube.com/watch?v=FPlnXgelDEk.

${ }^{74}$ A. Sen, Resources, Values and Development (Oxford, 1984), pp. 513-515; T. Kim and S. Axelrod, "Direct Instruction: An Educators' Guide and a Plea for Action", The Behavior Analyst Today, vol. 6 (2005), pp. 111-123; see also Watt, "The implementation of the capabilities approach in Cape York: Can paternalism be a pre-condition for participation?".

${ }^{75}$ See M. J. Snel, J. Terwel, C. A. J. Aarnoutse, and J. F. J. van Leeuwe,- Effectiveness of guided coconstruction versus direct instruction for beginning reading instruction ${ }_{2}=$ Educational Research and Evaluation, 18 (2012), pp. 353-374.

${ }^{76}$ A. Luke, "Back to the Future", Australian Educator, vol. 80 (2013), pp. 14-15.

${ }^{77}$ See D. Dean and D. Kuhn, "Direct Instruction vs. Discovery: The Long View", Science Education, vol. 91 (2006), pp. 384-397.
} 
they may be able to learn rules, they may be less able to think on their feet as new challenges emerge or lack the curiosity and interest needed to deal with complexity. ${ }^{78}$

Pearsen might claim that, while capabilities is a general, political liberal theory of justice, upholding the right of people to pursue plural conceptions of the good, he is acting, here, to advance one conception of the good internally within an Aboriginal context to promote most effectively a particular people's well being. Yet, even if that were his argument, Pearson cannot prescribe a programme of functioning for entire eommmnities within the broader confines of political liberalism. While capabilities are multiply realisable and need to be tailored to the particular cultural and environmental eontext within which they operate, the priority of liberty means that capabilities cannet be an entry route into a form of devolved perfectionism. People need, collectively, to elect to pursule a conception of the good under conditions of liberty in order that practical reason be developed and exercised.

The point of practical reason is to enable people to navigate through the increasingly complex and intricate relationships, circumstances and possibilities they face. Practical reason enables people, pragmatically, to identify and promote their interests and the interests of those around them by working with particular people and resources within particular contexts and roles. Practical reason can only be developed through exercise - it is practical for that very reason. It requires elements of trial and error, since, by their very nature, the people, circumstances and contexts we encounter have features which are not immediately obvious to us, however well we understand reason in the abstract. DI is crude insofar as choices are seen as constant sources of confusion and potential harm, with methodical, almost scriptural adherence to preordained pathways promoted as means of avoiding having to make choices in the reflective way those with practical reason do. ${ }^{79}$ Put simply, it is not the optimal means of engendering "the rational base... that is needed for sustained intellectual engagement and the formation of personal intellectual goals". ${ }^{80}$ It does not, in fact, lead to the expansive ability to "access, understand, analyse and evaluate information, make meaning, express thoughts and emotions, present ideas and opinions, interact with others and participate in activities at school and in their lives beyond school", which the Australian Curriculum Assessment and Reporting Authority ${ }^{81}$ insists defines literacy.

In the modern world, we need constantly to exercise practical reason in new and changing contexts. Our success in relationships and professions requires that we appreciate that single interpretations are seldom possible or beneficial. If we want to succeed, including on Pearson's terms, we often need to acknowledge the radical complexity of life and the radicaldeficiency of single interpretation perspectives. While

\footnotetext{
${ }^{78}$ See S. Vassallo, "Critical Pedagogy and Neoliberalism: Concerns with Teaching Self-Regulated Learning”, Studies in Philosophy and Education, vol. 32 (2013), pp. 563-580.

${ }^{79}$ See T. Chilcott, "Leading indigenous educator Chris Sarra slams teaching approach used in $\$ 7.72 \mathrm{~m}$ Cape York trial", The Courier Mail (October 9 2012), accessed December 5, 2014 http://www.couriermail.com.au/news/queensland/leading-indigenous-educator-chris-sarra-slamsteaching-approach-used-in-772m-cape-york-trial/story-e6freoof-

1226490937841?nk=2993794470ec5ee29fcc003e560be8b1; Direct Instruction Teaching, "Zig Engelmann Discusses Direct Instruction". See also B. Louden, "Direct Instruction and the Teaching of Reading”, The Conversation, (17 July 2014), accessed December 5, 2014 http://theconversation.com/direct-instruction-and-the-teaching-of-reading-29157.

${ }^{80}$ D. Kuhn, "Is Direct Instruction an Answer to the Right Question?", Educational Psychologist, vol. 42 (2007), p. 112.

${ }^{81}$ Australian Curriculum Assessment and Reporting Authority, General Capabilities in the Australian Curriculum (2013), accessed December 2014, http://www.australiancurriculum.edu.au/GeneralCapabilities/General\%20capabilities.pdf, p. 9.
}

Commented [MB4]: Maybe we 'accept' this change before sending in (that is, if you agree with my moving this chapter to the end - just before the conclusion - and the other changes I have made /added to it. 
it is understandable that Pearson should wish Aboriginal people to enjoy the advantages of economic and social advancement, it is not clear that the methods he proposes are the means by which to achieve that in the potentially rich and innovative forms that could emerge. We should not think that the regimented form of education proposed is a particularly effective means of providing people with the same capabilities provided by other forms of education, since it actively stifles the sort of exploratory work essential to forms of intellectual development associated with the dynamic and rich lives that the capabilities approach opens onto.

This is independent of the critical pedagogical notion that the oppressed are oppressed by having, as Freire puts it, their expectations shaped externally:

Integration results from the capacity to adapt oneself to reality plus the critical capacity to make choices and to transform that reality. To the extent that man loses his ability to make choices and is subject to the choices of others, to the extent that his decisions are no longer his own because they result from external prescriptions, he is no longer integrated... If man is incapable of changing reality, he adjusts himself instead. ${ }^{82}$

In the colonial context in which Pearson expresses concern at assimilation, it must be troubling that DI places such power in the hands of curriculum developers to identify and shape choices. It is certainly not clear that this promotes capabilities.

The "real economy"

In general, though, the development of capabilities does not always seem of primary importance in Pearson's work. Whereas in Sen and Nussbaum, the ultimate end of public policy is the provision, development and expansion of capabilities as ableness, in Pearson's work, there is a clear commitment to the promotion of a particular conception of the good. ${ }^{83}$ This is apparent in his 2005 report on the Economic Viability of Remote Communities, in which he highlights three means of ensuring viability: enhancement of capabilities and mobility; enablement of engagement with the "real economy" by policies and attitudes; and engagement of people in both local and nonlocal employment. ${ }^{84}$

In the first instance, the holistic value of productive, but economically unprofitable, activities is overlooked ${ }^{85}$ while questions about the value of the "real economy" are ignored. Pearson neglects, for example, to acknowledge the fact that the viability of life in rural areas has been threatened directly by the "real economy" 86 and that the historical decision of pastoralists to dispense with Aboriginal labour rather than

\footnotetext{
${ }^{82}$ P. Freire, Education for critical consciousness, (New York, 1987), p. 4.

${ }^{83}$ See Pearson, The Cape York Agenda: Fundamental Transformation through Radical Reform; Watt, "The implementation of the capabilities approach in Cape York: Can paternalism be a pre-condition for participation?"-

${ }^{84}$ N. Pearson, Economic Viability of Remote Communities (Cairns, 2005); Pearson and L. KostakidisLianos, Building Indigenous Capital: Removing Obstacles to Participation in the Real Economy.

${ }^{85}$ See A. Lattas and B. Morris, "The Politics of Suffering and the Politics of Recovery", in Culture Crisis: Anthropology and Violence in Aboriginal Australia, ed. J. Altman and M. Hinkson (Kensington, 2010), pp. 61-87; M. Hinkson, "Western Innocence”, Arena vol. 118 (2012), pp. 35-36; J. Coghlan, "Income Management", Arena, vol. 118 (2012), pp. 19-21;

${ }^{86}$ See A. M. Dockery, "Culture and Wellbeing: The Case of Indigenous Australians", Social Indicators Research, vol. 99, 2 (2010, pp. 315-332 and Altman's work on the hybrid economy, "Alleviating poverty in remote Indigenous Australia: The role of the hybrid economy".
} 
adhere to equal pay legislation (the turn of events which leads to "passive welfare") ${ }^{87}$ was due to their concern for profitability in the "real economy". ${ }^{88}$ As Altman has emphasised, there may be many areas of importance to people which are not viable in the "real economy". ${ }^{89}$ In the second instance, capabilities slip from integral constituents of viable human development to mere instruments of a very narrow conception of economic viability.

If the concern is capabilities, the relationship should be inverted, with the economy guided and bent to the advancement of human interests as means of expanding ableness. This does not deny the capacity of engagement with the "real economy" to promote those interests, particularly by providing resources for self-development and relationship sustenance in different ways. However, Pearson's treatment of the topic highlights his misunderstanding or misuse of the capabilities approach, such that he ends up trying to use capabilities to justify, rather than oppose, constraints on autonomy.

Tensions, possibilities and empathy

Pearson consistently highlights the "tension" between traditional Aboriginal cultural commitments and integration in the "real economy" through the following binary distinctions: "immediate sharing and individual accumulation; loyalty to kin and impartiality to all; individual autonomy and the authoritarian practices of the school and workplace; individual advancement and remaining at one with the community, and exploiting land and living with it"..$^{90}$ Although he refers to these as tensions in need of compromise, there is a sense that, in order to achieve progress, more compromise will be needed from those who endorse traditional commitments, than those who seek to introduce change. This is apparent in his powerful criticism of double standards among those on the left who have benefited from self-interest, but attempt to dissuade Aboriginal people from pursuing a similar path:

We need policies that increase self-regard among the disadvantaged. To put it crassly: poor people need to become at least as self-regarding as those who are not poor. Until disadvantaged people become as self-interested as advantaged people, they will not rise above their disadvantage. Until we crank up the engine of self-interest among the under-privileged, we won't get individual, and therefore social, uplift. ${ }^{91}$

For Pearson, "Self-interest for too many progressives is anathema to social justice, when in fact it is the very engine of the justice that is sought". 92 The problem with this

\footnotetext{
${ }^{87}$ Watt, "The implementation of the capabilities approach in Cape York: Can paternalism be a precondition for participation?", p. 39

${ }^{88}$ See Pearson, "White Guilt, Victimhood and the Quest for a Radical Centre"; Langton, "A New Deal? Indigenous Development and the Politics of Recovery"; Pearson, Up from the Mission: Selected Writings, p. 159; J. Altman, "The Future of Indigenous Australia: Is there a Path beyond the Free Market or Welfare Dependency?", Arena Magazine, vol. 84 (August-September 2006), accessed December 5 , 2014, http://caepr.anu.edu.au/sites/default/files/publications/topical/Altman_Future.pdf.

${ }^{89}$ Altman, "Alleviating poverty in remote Indigenous Australia: The role of the hybrid economy".

${ }_{90}$ Pearson, The Cape York Agenda: Fundamental Transformation through Radical Reform, pp. 5-6.

${ }^{91}$ Pearson, "Nights when I dream of a better world: Moving from the centre-left to the radical centre of Australian politics".

92 N. Pearson, 2013 Whitlam Oration, (University of Western Sydney, 13 November 2013), accessed December 5, 2014, http://australianpolitics.com/downloads/2013/13-11-13_whitlam-oration_noelpearson.pdf.
} 
is that the-sort of self-interest advocated may ensure cultural convergence with the mainstream (something which Pearson ${ }^{93}$ himself regards as problematic), but and there is little empirical evidence to suggest that it results in a general uplift in social conditions (unless measured according to narrow criteria), even if there is evidence that it may contribute to economic growth. Given that Pearson's ${ }^{94}$ Button Oration was an attempt to stoke change in the left, it seems reasonable for the left to retort that the "real economy" has hardly been an unalloyed success (witness the Global Financial Crisis of 2007-2008) and that opening up Aboriginal communities (where possible) to the "real economy" therefore creates new opportunities for people to be subject to additional deleterious inequalities and pathologies. While at least some members of Aboriginal communities may find their material conditions improved, there is nothing to guarantee improvements across the board.

Pearson's account of prospective responsibility is one in which welfare services are pushed back and people forced to seek sustenance from productive activity, while his account of responsibility as agency is reduced to fulfilment of a duty not to burden others. In this respect, Pearson ${ }^{95}$ appears keen to replicate the unforgiving natural environment of the hunter gathering past, in an unforgiving capitalist social environment of the present. While not burdening others with frivolous or vexatious behaviour seems a reasonable account of responsibility, doubts about the viability of the "real economy" replacing welfare in certain regions of Australia not only means that the empirical claim of prospective responsibility is challenged, but that responsibility as agency is called into question. This is because certain people will necessarily lack the resources to sustain themselves precisely because of the economy's concern for efficiency and profit. Under these conditions, there is the risk that personal responsibility as agency may be seen to equate to quiet self-harm for those who fail, and guilt-free self-indulgence for those who succeed, since, in the absence of demand sharing, success in acquiring resources means that responsibility as agency is exercised in full.

Beyond this, there is the possibility that promoting the sort of competitive selfinterest which Pearson articulates may lead, as it has elsewhere, to "responsible" individuals actively excluding "failures" as they pursue their interests unshackled by demand sharing. While, on some crude utilitarian calculation, the emergence of wealthy, responsible entrepreneurs may appear to be an improvement on conditions elsewhere, according to the capabilities approach, we should regard with great regret the emergence of serious asymmetries, especially where material inequalities open up opportunities for legal and political ones. It is naturally the case, here, that successful, "responsible" people have greater access to the means by which to monopolize political positions, excluding less "responsible" individuals and, cyclically, helping to create the legislative environment to consolidate wealth. ${ }^{96}$ Responsibility, as Pearson articulates it, will not prevent this.

\footnotetext{
${ }^{93}$ Pearson, "Radical Hope: Education and Equality in Australia"; Pearson, "A Rightful Place: Race, Recognition and a More Complete Commonwealth".

${ }^{94}$ Pearson, "Nights when I dream of a better world: Moving from the centre-left to the radical centre of Australian politics".

${ }^{95}$ E.g. Pearson, "Nights when I dream of a better world: Moving from the centre-left to the radical centre of Australian politics"; Pearson, "Shared Descent into the Maelstrom of Addiction".

${ }^{96}$ See R. Folds, Crossed Purposes: The Pintupi and Australia's Indigenous Policy (Sydney, 2001), pp. 51, 57, 59; P. Toohey, "Last Drinks: The Impact of the Northern Territory Intervention", Quarterly Essay, vol. 30 (2008), p. 67.
} 
At a structural level, as has been argued elsewhere, ${ }^{97}$ capabilities can only be developed fully through relationships guided institutionally by cultural commitment to multiply realizable core values of solidarity, equality and non-domination. While those values may look different in different contexts, their effect should be the same - to check other values which would otherwise serve to undermine broader human interests by facilitating selfish behaviour, denying certain individuals the resources to sustain themselves and subjugating people to the whims of others. One possible interpretation of Pearson's concern with demand sharing is that he actually sees the absence of solidarity and non-domination in its contemporary form, since irresponsible people who demand share fail to recognize the deleterious, burdensome effect it can have on others. These people undermine core values because they suffer from the failure to develop practical reason, but also emotions, such as empathy, which Nussbaum includes articulate as a latent capability. ${ }^{98}$ When deployed successfully in accordance with practical reason, empathy enables people to recognize the effects of their behaviour and take steps to uphold the interest of others. However, it is often the case that the competitive system which Pearson advocates undermines empathy, rewarding behaviour unchecked by concern for failure and the sort of core values which might promote everyone's interests.

Of course, Pearson may claim that while capabilities is a general liberal political theory of justice upholding the right of people to pursue plural conceptions of the good, he is acting to advance one conception of the good internally within Aboriginal contexts to promote most effectively the well-being of Aboriginal people. In effect, capabilities are one thing, but Pearson is doing something else. Yet Pearson does not argue this. Rather, he attempts - mistakenly we have shown - to leverage the capabilities approach to prescribe personal responsibility, Direct Instruction Teaching, and engagement with the "real economy". 99 Furthermore, even if this were Pearson's argument, he cannot legitimately prescribe a programme of functioning for entire communities within the broader confines of Australian political liberalism. While capabilities are multiply realisable and need to be tailored to the particular cultural and environmental context within which they operate, the priority of liberty means that capabilities cannot be an entry route into a form of devolved perfectionism by allowing individuals to prescribe functioning. People need, collectively, to elect to pursue a conception of the good under conditions of liberty in order that practical reason be developed and exercised.

\section{Conclusion}

Pearson is surely right to state that there are certain issues, including alcohol abuse and the modern economy, which pre-colonial Aboriginal society could not possibly have foreseen and for which new responses are required. There is also little doubt that personal responsibility is a laudable personal practice which is central to societal wellbeing. However, some of the policy responses that Pearson advocates require much more thinking through, not least because they are not consistent with the capabilities approach which he uses as justification and have been promoted and practised with mixed success elsewhere. One of the key problems that people face, today, is that the socio-economic conditions which are associated with neo-liberal reforms engender forms of precariousness which promote irresponsibility. As Guy Standing ${ }^{100}$ has

\footnotetext{
${ }^{97}$ Johnson, Evaluating Culture.

${ }^{98}$ Nussbaum, Women and Human Development, p. 79.

${ }^{99}$ It may be that the ethical individualism internal to the capabilities approach helps to facilitate such a misreading, but as we have shown, the misreading is Pearson's.

Commented [MB7]: Matt, hope the footnote below doesn't seem too 'dropped in'. I think it'd be good to keep it if possible... it's a useful idea.

Commented [MJ8R7]: Yep - that's an important point

Commented [MB9]: Seem a bit dense to me. Why not just 'prescribing functioning" as we've used earlier.
Formatted: English (United States)

Formatted: Justified 
argued, engagement with the "real economy", and its unforgiving precarious conditions, leads people to treat work and other money-making activities instrumentally in the absence of stable sources of employment, leaving no "shadow of the future" hanging over their actions and little incentive to sustain long-term relationships or a broader range of productive, but unpaid, socio-cultural activities. Far from engendering responsibility, these conditions can undermine the sort of rich, meaningful lives that the capabilities approach endorses.

A clearer understanding of capabilities supports two challenges to Pearson's work: First, to political attempts to impose forms of functioning (particularly personal responsibility) on individuals and groups, especially in cases in which those forms are narrow and second, to the "real economy" and its associated values. While other approaches may justify the kind of programmes Pearson supports, only a very unorthodox and problematic understanding of capabilities can lead to the prescriptive and potentially authoritarian and inegalitarian conclusions he draws. To build on the capabilities approach in Aboriginal affairs in order to promote rather than restrict human flourishing requires more attention to capabilities as ableness. In this respect, there may be productive and effective means of incorporating traditional Aboriginal cultural commitments in ways that avoid the very assimilation that Pearson criticizes. ${ }^{101}$

Given the problematic fit of Pearson's policy agenda with the capabilities approach, the reasons for Pearson using capabilities at all are elusive. In the first instance,-Pearson is surely right to believe that we should be responsible. Indeed, historically, groups, like the one with which he identifiesincluding Australian Aboriginal peoples, created and upheld institutions which fostered responsibility. One major problem, which Pearson accepts, is that the disruption of colonialism has undermined systematically the ability of people collectively to sustain those older systems, to revise and adapt certain institutions to deal with challenges which could never have been predicted or to develop new institutions independently of Government constriction. In this context, one may speculate that Pearson deploys capabilities as a means of transcending discoursesEuropean and Aboriginal worlds, presenting a wellrespected approach intelligible to European-policy makers as a means of carving out space for Aboriginal people and communities to advance institutions under the conditions of colonialism, and with the intention of enhancing, autonomy. If that is the case, the autonomy carved out may be a hollow one, $s$ since as the Global Finance Crisis and subsequent revelations demonstrate, it is precisely the naked instrumentalism of neoliberalism, among other phenomena,- which has can - undermined people's abilityopportunities to pursue rationally self-interest achieve well-being. In neoliberalism it seems seldom that being real means being responsible. A more careful reading and application of the capabilities approach than that offered by Pearson to date may promote personal responsibility, but it requires keeping the principle of liberty to the fore. Such an approach would also facilitate engagement with Aboriginal cultural commitments, thereby going some way to support Pearson's stance against assimilationist policy agendas.

If he wants people to be responsible and show concern for others in promoting their well-being, then he needs more critically to consider the impact the culture of the real economy. In light of the Global Finance Crisis and subsequent revelations about a

\footnotetext{
${ }^{101}$ Pearson, "Radical Hope: Education and Equality in Australia"; Pearson, "A Rightful Place: Race,
} Recognition and a More Complete Commonwealth". 
profession supposedly at the heart of that economy, it seems seldom that being real means being responsible.

Formatted: Indent: First line: $1.27 \mathrm{~cm}$ 